\title{
Development of a GIS based Multicriteria Decision Support System for Organic Waste Management: Izmir Case Study
}

\author{
Sedat Yalcinkaya ${ }^{1}$, Osman Sami Kirtiloglu² \\ ${ }^{1}$ Izmir Katip Celebi University, Faculty of Engineering and Architecture, Department of Environmental Engineering \\ Balatcik 35620, Cigli, Izmir, Turkey \\ sedat.yalcinkaya@ikc.edu.tr \\ ${ }^{2}$ Izmir Katip Celebi University, Faculty of Engineering and Architecture, Department of Geomatics Engineering \\ Balatcik 35620, Cigli, Izmir, Turkey \\ osmansami.kirtiloglu@ikc.edu.tr
}

\section{Extended Abstract}

The purpose of this research is to develop a geographic information system (GIS) based multicriteria decision support system that can take into account environmental and economic factors for modeling and comparison of incineration, anaerobic digestion and composting technologies in organic waste management system (organic municipal solid waste and livestock manure); and to implement the system by performing a case study for the City of Izmir.

Regulations limiting the disposal of organic municipal solid waste at landfills and application of livestock manure to fertilize agricultural lands together with energy and compost production purposes increased the application of various organic waste management technologies. Because organic waste is distributed dispersedly, finding the optimal number, capacity, and sites for organic waste management facilities are key issues to minimize transfer costs and transfer-induced $\mathrm{CO}_{2}$ emissions. GIS combined with multicriteria decision making (MCDM) methods have been used to assess biomass availability and suitable plant sites in some studies, for instance, [1]-[5]. However, there is still a need for a decision support system that systematically evaluates qualitative and quantitative criteria for complex multicriteria decisions to design, evaluate and prioritize decision alternatives in order to assess sustainability of organic waste management technologies.

An integrated approach of fuzzy logic and analytical hierarchy process MCDM methods and GIS is being used to model incineration, anaerobic digestion and composting technologies for organic waste management. The methodology includes; development of a proper geospatial database for organic waste, analysis of spatial distribution and energy potentials of organic waste, pre-screening process for suitable plant sites, determination of potential plant sites by multicriteria decision analysis, determination of locations and capacities by p-median solution approach, number and capacity of the system in relation to economic sustainability, and cost-benefit analysis. This methodology is being implemented for the first time to determine the optimal number, capacity, and plant sites for various organic waste management technologies through integration of environmental and economic factors. This research represents a big step in establishment of local decision support system on organic waste management.

An extensive work put into data collection and development of the geospatial database. Spatial availability and energy potentials of organic municipal solid waste and livestock manure were analyzed. Areas that are environmentally sensitive and limited in use by regulations were excluded with the aid of GIS. Three different organic waste management scenarios were investigated based on the needs of City of Izmir; 1) incineration of mixed municipal solid waste and anaerobic digestion of livestock manure, 2) anaerobic co-digestion of organic municipal waste and livestock manure, and 3) composting of organic municipal waste and livestock manure. Daily energy potentials were calculated as $14.47 \mathrm{TJ}$ and $7.95 \mathrm{TJ}$ for scenario 1 and 2, respectively. 8805 ton/day compost production was calculated for scenario 3.

\section{Acknowledgement}

The authors would like to thank TÜBİTAK, the Scientific and Technological Research Council of Turkey, (Grant number 118Y043) for funding this research. 


\section{References}

[1] B. Sliz-Szkliniarz and J. Vogt, "A GIS-based approach for evaluating the potential of biogas production from livestock manure and crops at a regional scale: A case study for the Kujawsko-Pomorskie Voivodeship," Renew. Sustain. Energy Rev., vol. 16, no. 1, pp. 752-763, Jan. 2012.

[2] J. Höhn, E. Lehtonen, S. Rasi, and J. Rintala, "A Geographical Information System (GIS) based methodology for determination of potential biomasses and sites for biogas plants in southern Finland," Appl. Energy, vol. 113, pp. 1-10, 2014.

[3] A. Zubaryeva, N. Zaccarelli, C. Del Giudice, and G. Zurlini, "Spatially explicit assessment of local biomass availability for distributed biogas production via anaerobic co-digestion - Mediterranean case study," Renew. Energy, vol. 39, no. 1, pp. 261-270, 2012.

[4] A. Sultana and A. Kumar, "Optimal siting and size of bioenergy facilities using geographic information system," Appl. Energy, vol. 94, pp. 192-201, 2012.

[5] S. Silva, L. Alçada-Almeida, and L. C. Dias, "Biogas plants site selection integrating Multicriteria Decision Aid methods and GIS techniques: A case study in a Portuguese region," Biomass and Bioenergy, vol. 71, pp. 58-68, 2014. 